\title{
Análise da Produção Científica a partir da Redução Sociológica de Guerreiro Ramos
}

\section{Analysis of Scientific Production From The Sociological Reduction Of Guerreiro Ramos}

\author{
Raphaela Reis Conceição Castro Silva ${ }^{1}$
}

\begin{abstract}
Resumo
Considerando que a ciência da administração se construiu a partir da influência norte-americana. É notório que tal influência persiste e ainda é fortemente percebida em nossos cursos de graduação e pós-graduação. Diante desse cenário, busca-se identificar a convergência entre a produção cientifica da Administração e o conceito de consciência crítica de Guerreiro Ramos. A intenção é examinar a produção da área da Administração por um outro enfoque, que privilegie o debate sobre a nossa sociedade e o bem-estar coletivo em um país com problemas expressivos e de uma desigualdade social e econômica abissal. Para tanto, foram analisados artigos científicos produzidos pelos grupos de pesquisa da área da Administração da UFMG, de acordo com primeira lei da redução sociológica de Ramos - a Lei do Comprometimento. Tal lei aponta para a necessidade de o cientista social adotar sistematicamente uma posição de engajamento ou de compromisso consciente com o seu contexto. Dentre os 303 trabalhos analisados, dois destes podem ser aplicados na Lei do Comprometimento o que representa um número muito baixo perto do tamanho da amostra analisada. Os resultados deste trabalho apontam para a necessidade de discutir e refletir mais aprofundamento sobre o papel da universidade, grupos de pesquisa e produção científica no tocante ao desenvolvimento e consciência crítica.
\end{abstract}

Palavras-Chave: Produção Científica, Guerreiro Ramos, Redução Sociológica.

\begin{abstract}
Considering that the science of administration was built from the American influence. It is well known that such influence persists and is still strongly perceived in our undergraduate and graduate courses. Given this scenario, we seek to identify the convergence between the scientific production of the Administration and the concept of critical conscience by Guerreiro Ramos. The intention is to examine the production of the Administration area using another approach, which privileges the debate about our society and the collective well-being in a country with significant problems and abysmal social and economic inequality. For this purpose, scientific articles produced by research groups in the Administration area at UFMG were analyzed, according to the first law on the sociological reduction of Ramos - Commitment Law. This law points to a need for the social partner to systematically adopt a position of commitment or conscious commitment to its context. Among the 303 studies analyzed, two of these can be applied in the Commitment Law, which represents a very low number close to the size of the analyzed sample. The results of this work point to the need to discuss and reflect more deeply on the role of the university, research groups and scientific production regarding development and critical awareness.
\end{abstract}

Keywords: scientific production, sociological reduction, Guerreiro Ramos.

\footnotetext{
${ }^{1}$ Professora de Gestão Pública do Instituto Federal do Rio de Janeiro. Doutora em Administração pela Universidade Federal de Santa Catarina (UFSC), na linha de pesquisa em Organizações, Sociedade e Desenvolvimento. Mestre em Administração pela Universidade Federal de Lavras (UFLA), na linha de pesquisa em Organizações, Gestão e Sociedade. Possui MBA em Gestão de Pessoas pela Universidade Federal de Juiz de Fora (UFJF) e especialização em Planejamento e Gestão de Educação a Distância pela Universidade Federal Fluminense (UFF). castroreis@gmail.com
}

Artigo recebido em: 02 de agosto de 2020. Artigo aceito em 15 de dezembro de 2020. 


\section{Introdução}

A ciência da administração se construiu a partir da influência norte-americana. Nossos primeiros cursos foram moldados sob essa influência, bem como nossas primeiras produções cientificas. Contudo, é notório que tal influência persiste e ainda é fortemente percebida em nossos cursos de graduação e pós-graduação. Diante desse cenário, busca-se examinar a produção da área da Administração por um outro enfoque, que privilegie o debate sobre a nossa sociedade e o bem-estar coletivo em um país com problemas expressivos e de uma desigualdade social e econômica abissal. Portanto, o campo de estudos da Administração é um campo fértil para importantes reflexões como a proposta por este estudo.

Para tanto, retornamos ao intelectual engajado Guerreiro Ramos como ferramenta analítica de tais produções. Além disso, utilizamos também as ideias de desenvolvimento de Celso Furtado como norteador dessas análises. As hipóteses que aqui serão propostas buscarão sustentar que o papel da universidade é fundamental. Tal como propõe Tragtenberg (1979, p. 9), a universidade produz dois tipos de intelectuais,

O intelectual orgânico da burguesia, organizador da hegemonia
burguesa, a qual por mediação da universidade inculcará as
formas de sentir, pensar e agir da classe dominante como sendo
'naturais' e 'normais'; e o intelectual crítico que, em épocas de
ascensão do movimento de massas, pode legitimamente
representa-las.

Por meio da intelectualidade crítica é possível vislumbrar outras possibilidades em contextos solidários, cooperativos, através de parcerias entre pesquisadores e sindicatos, organizações não governamentais, movimentos sociais, grupos sociais especialmente vulneráveis (imigrantes ilegais, desempregados, doentes crônicos, idosos etc.), comunidades populares, grupos de cidadãos críticos e ativos. Ramos (1958) apresenta a consciência crítica que levaria a criação intelectual a refletir sobre as transformações necessárias para levar o país ao desenvolvimento e autonomia intelectual.

Assim, o objetivo desse trabalho é identificar a convergência entre a produção cientifica da Administração e o conceito de consciência crítica de Guerreiro Ramos.

O trabalho está estruturado em cinco partes, além desta introdução. A seção dois atenta aos fundamentos teóricos, apresenta as reflexões de Guerreiro Ramos sobre a ideia de consciência crítica. $\mathrm{Na}$ seção seguinte tratar-se-á dos procedimentos 
metodológicos. Na quarta seção, constam os resultados encontrados e, em seguida, as considerações finais deste estudo.

\section{GUERREIRO RAMOS E A CONSCIÊNCIA CRÍTICA}

Guerreiro Ramos, jornalista, ensaísta e poeta, foi um intelectual militante dedicado à tarefa de descontruir a ciência social que se imponha no Brasil nos anos de 1940, partindo do pressuposto de vinculação entre o desenvolvimento literário e a identidade nacional (AZEVÊDO, ALBERNAZ, 2010). Seu apelo se dirigia à autonomia intelectual e à incorporação da nacionalidade brasileira nas produções. Contudo, ainda é esquecido por muitos (COSTA, 2012). Para Guerreiro, os anos de 1950 foram fundamentais para a identificação de nossa personalidade histórica. Estes, por seu turno, foram marcados pelos tempos de $\mathrm{JK}$, pelo crescimento acelerado e pela euforia do desenvolvimento, haja vista que nossa soberania não era ameaçada e nenhuma forma de dominação cultural nos sufocou (COSTA, 2012). Ramos atuou junto ao Instituto Superior de Estudos Brasileiros (ISEB) e possuía uma visão nacionaldesenvolvimentista.

Suas preocupações metodológicas continuam atuais, em especial a crítica na eficácia imanente das teorias e instituições importadas (PAULA, 2015). A obra de Guerreiro Ramos é considerada fecunda, pioneira e singular, e muito tem a contribuir com a ciência da administração (SANTOS, 2001). Ele teorizou sobre sociologia, teoria das organizações e administração pública. Pode ser considerado o único teórico brasileiro no campo da administração (MARTINS, 2012; TENÓRIO, 2012). A produção guerreirista está sempre comprometida com a transformação do social (COSTA, 2012),

\section{O legado de Guerreiro Ramos}

Não é possível reler Guerreiro Ramos sem considerar a historicidade de seu pensamento. Haja vista a influência que os anos 50 exerceu em seu pensamento e nas possibilidades de desenvolvimento para o país (COSTA, 2012). Assim, Martins (2012) destaca três momentos em sua obra. O primeiro deles é quando o sociólogo propõe a redução sociológica em 1965, método que privilegia a redução do pensamento social 
produzido em outros contextos, para que fosse possível liquidar a mentalidade colonial. Assim, também Misoczky (2006) afirma que é necessário “descolonizar” a pesquisa acadêmica, que indica a busca pela liberdade de nossos modos de elaborar e reconhecer o mundo, lançando mão da dominação das heranças do "eurocentrismo".

A segunda reflexão é sobre os modelos de homem e a teoria organizacional em 1971. Sua proposição- homem parentético- é assim resumida: “(...) atribui importância ao seu eu e aos seus valores; busca permanentemente um significado para a vida; tem consciência crítica altamente desenvolvida; é criativo e empreendedor; tem autoestima e autonomia; é um 'ser em suspenso"” (MARTINS, 2012, p. 438).

O terceiro momento é o da publicação da obra A nova ciência das organizações: uma conceituação da riqueza das nações na qual Guerreiro apresenta o paradigma paraeconômico, configurando o mercado como um enclave social legítimo e necessário.

Em face do caráter que representa para os propósitos deste trabalho, nos debruçaremos sobre o primeiro momento da obra guerrerista: a redução sociológica, sendo um método adequado e pertinente para analisarmos as produções cientificas das ciências administrativas e muito útil para a assimilação crítica da produção intelectual estrangeira (COSTA, 2012). Especialmente a primeira lei do método da redução sociológica.

\section{A Redução Sociológica: um método para a assimilação crítica}

Aborda-se a contribuição da redução sociológica, conceito formulado por Ramos como referencial analítico, para a compreensão e condução da prática intelectual da ciência administrativa na atualidade. As bases filosóficas desse pensamento proposto por Ramos trata-se de um esforço semelhante ao que Husserl fez ao conceito de redução fenomenológica, contudo, busca a essências das coisas para o campo da análise organizacional (PAULA, 2005; BERQUE; KLERING, 2010; COSTA, 2012; VIEIRA; RIVERA, 2012).

Já os antecedentes sociológicos da redução se encontram no âmbito da Sociologia do Conhecimento, em especial, entre os adeptos da fenomenologia como Max Scheler, Alfred Schutz, Georges Gurvitch e especialmente Karl Mannheim, que é considerado, por Guerreiro Ramos, a fonte da redução sociológica. O historicismo, a fenomenologia, a sociologia do conhecimento e o existencialismo constituem as bases 
do pensamento de Guerreiro Ramos (PAULA, 2005; COSTA, 2012).

Destaca-se que a proposta nasce em um contexto de formação das ciências sociais no Brasil. Nesse processo, opunha-se a corrente dominante, se que apropriava diretamente da produção intelectual estrangeira. Ramos (1958) não desconsiderava a validade do conteúdo, contudo, enfatizava o devido filtro crítico-assimilativo (BERQUE, KLERING, 2010). Portanto, todo cientista social pode utilizar de conteúdo estrangeiro, desde que submetido a um crivo crítico.

$\mathrm{Na}$ visão dele, a sociologia nacional deveria realizar uma autocrítica para colaborar com a autoconsciência nacional, ganhando uma funcionalidade, intencionalidade e organicidade, elementos que a transformariam numa teoria militante da própria realidade nacional. Para evitar a hipercorreção, Ramos elabora uma técnica de redução sociológica, cujo objetivo é habilitar o estudioso a examinar os produtos sociológicos a fim de assimilá-los, sem perigo de deixar-se envolver por sua intencionalidade ou de se alienar (PAULA, 2005).

"No domínio restrito da sociologia, a redução é uma atitude metódica que tem por fim descobrir os pressupostos referenciais, de natureza histórica, dos objetivos e fatos da realidade social” (RAMOS, 1958, p. 82). Essa atitude não está relacionada apenas ao conhecer, mas também à necessidade social de uma comunidade, que necessita da experiência de outras comunidades - tal como é o desenvolvimento. Cumpre salientar que a redução sociológica não se trata de isolacionismo e muito menos de exaltação romântica do local, regional ou nacional, mas sim de uma consciência crítica ou melhor de critérios de seletividade.

\section{Características Essenciais da Redução Sociológica: as quatro leis}

Com a intenção de delinear o método, Ramos discute as características essenciais da redução sociológica, propondo quatro leis. A primeira- a lei do comprometimentofoi enunciada por Ramos (1958) da seguinte maneira: nos países periféricos, a ideia e a prática da redução sociológica somente poderiam ocorrer ao cientista social que tivesse adotado sistematicamente uma posição de engajamento ou de compromisso consciente com o seu contexto.

Antes de justificar essa afirmação, o autor entende que são necessários alguns esclarecimentos, uma vez que o sentido da lei de comprometimento se esclarece a partir do reconhecimento da diferença essencial entre o engajamento sistemático e o 
engajamento ingênuo. Não obstante, Ramos (1958) afirma que os cientistas sociais geralmente desejam contribuir para a promoção histórica de sua coletividade.

A posição de engajamento é baseada numa crítica radical, ou seja, numa reflexão sobre os fundamentos existenciais da ciência em ato ou da produção científica. $\mathrm{Na}$ realidade, este engajamento ou compromisso, na medida em que seja sistemático, posiciona o cientista no ponto de vista universal da comunidade humana. Portanto, o regional e o nacional, nesse contexto, são termos imediatos da concretização do universal. Assim, o comprometimento sistemático confere lucidez ao cientista, pois o leva a colocar, sob a luz da consciência, as virtualidades obscurecidas na conduta ordinária.

[Esse] é o requisito para que possa emergir, nos países subdesenvolvidos, a verdadeira ciência. Além disto, é também condição indispensável para que o cientista destes países se libere da 'servidão intelectual', ou seja, transcenda a condição de copista e repetidor, e, assim, ingresse num plano teórico eminente (RAMOS, 1958, p. 76).

O sociólogo, como qualquer outro especialista em ciências sociais, está sempre condicionado a um caráter existencial, tenha ou não consciência disso. $\mathrm{O}$ eu e a consciência do eu emerge do "nós", que antecede à lógica e à história. Em contrapartida, a consciência ingênua não percebe a implicação recíproca do ser humano e do mundo. "Ao refletir sobre os supostos da atividade científica, ver-se-á que está implicada numa teia de relações complexas que constituem o mundo tal como aparece ao cientista que nele vive" (RAMOS, 1958, p. 77).

“Tenha ou não consciência disto, o homem não é um termo isolado da realidade histórico-social" (RAMOS, 1958, p. 79). Toda atividade humana implica uma interpretação das coisas que manipula, assim como o processo de teorização é extensão do fazer ao nível da representação. É justamente por isso que não é legítimo distinguir teoria e prática. Supor que o homem teoriza primeiro e age depois é incorrer em erro. $\mathrm{O}$ homem não se esgota no pensar; é também sentir e querer. É a reflexão que torna explícita e exprime de modo elaborado, a virtualidade explícita no agir humano.

Guerreiro Ramos (1958) contextualiza essa afirmação nas diferentes áreas de conhecimento, para então discutir as diferenças entre os estudos de países dominantes e países subdesenvolvidos.

O projeto de desenvolvimento de uma região atrasada não afeta, não configura, o destino de um europeu ou norte-americano. Mas configura normalmente o destino dos naturais desta região. $O$ homem não é apenas um ser-no-mundo, é também um ser-do-mundo, em determinada 
forma histórica particular (RAMOS, 1958, p. 81-82).

Para conseguirmos "enxergar" nossa região, é preciso "desideologizar" nosso olhar e adotar um ponto de vista universal da comunidade humana (RAMOS, 1958).

Nos países periféricos é a adoção sistemática de um ponto de vista universal, orientado para o futuro, que possibilita a redução sociológica. É o imperativo de acelerar, de modo historicamente positivo, a transformação de conceitos subdesenvolvidos quem impõem ao cientista de países periféricos a exigência de assimilar, não mecanicamente, o patrimônio científico estrangeiro (RAMOS, 1958, p. $82)$.

Essa exigência se torna aguda quando são deflagrados impulsos concretos de ordenação própria ou de articulação interna naqueles países, portanto, espaço ideal para a redução sociológica, que impõe aos cientistas assimilar não mecanicamente as contribuições cientificas estrangeiras. Para Ramos (1958), nesses países, a sociedade não está fundada segundo critérios próprios, mas a fundar. Dessa forma, assumir o engajamento abre um horizonte de infinitas possibilidades para o intelectual. Em outros termos, o comprometimento dos cientistas sociais é fundamental para método da redução sociológica.

A segunda lei corresponde à lei da redução sociológica, a qual pactua pela ideia de que "toda a produção científica estrangeira era de caráter subsidiário para o sociólogo que tenha adotado sistematicamente uma posição de engajamento ou de compromisso consciente com o seu contexto" (RAMOS, 1958, p. 113).

Um produto sociológico qualquer (sistema, teoria, conceito, técnica de pesquisa, método) é sempre elaborado para atender a uma determinada imposição. Assim, para a redução sociológica, o sujeito é o eu concreto, inserido na comunidade (RAMOS, 1958). Mediante redução sociológica, torna-se necessário descobrir o contexto de origem dos nóemas (conteúdo objetivo do ato intencional) e o sentido dado aos produtos sociológicos, para utilizá-los como subsídios para construção da matéria-prima teórica própria, condicionada a fatores particulares da sociedade em que vive (RAMOS, 1958).

O corpo social posiciona, diante do sociólogo, as tarefas que deve empreender, ou seja, essas tarefas não são determinadas puramente pelo gosto individual, visto que são determinadas pela comunidade. Nesse sentido, a prática da redução converte o sociólogo de consumidor para produtor de ideias. A produção estrangeira, para o sociológico que fundamenta sua atividade na prática social, não vale como paradigma ou modelo, mas apenas como subsídio (RAMOS, 1958). 
A terceira lei, a lei da universalidade dos enunciados gerais da ciência, prega que “a redução sociológica admite a universalidade da ciência tão somente no domínio dos enunciados gerais, não implicando, de modo algum, negar a universalidade da ciência. Seu propósito é, apenas, levar o cientista a submeter-se à exigência de referir o trabalho científico à comunidade em que vive" (RAMOS, 1958, p. 121).

Guerreiro Ramos (1958), então esclarece que uma sociologia se caracteriza como nacional, não pelo fato de que os princípios gerais do raciocínio científico variem de nação para nação, mas tão somente pela funcionalidade das cogitações do sociólogo, um ser em situação, histórico, ou seja, uma criatura humana. Nesse sentido, este cientista terá que apreender os objetos mediante o ponto de vista de sua situação ou daquilo que ele tem, como o corpo, condição social, local onde vive (bairro, cidade, país), profissão, época etc.

Por fim, a quarta lei - a lei das fases - diz o seguinte: "à luz da redução sociológica, a razão dos problemas de uma sociedade particular é sempre dada pela fase em que tal sociedade se encontra" (RAMOS, 1958, p. 129).

Essa lei propõe pensar os fatos sociais fundamentada na "razão sociológica" (RAMOS, 1958, p. 101), que corresponde à referência básica a partir da qual tudo o que acontece em determinado momento de uma sociedade adquire seu exato sentido. É impossível a compreensão adequadamente dos fenômenos mediante o mero conhecimento empírico imediato ou somatório das percepções diretas (RAMOS, 1958).

A lei das fases contribui para formar consciência de que diferentes seções do acontecer histórico têm limites, define um modo sociológico de pensar, a partir da razão sociológica. Sob aspectos relacionados às diferentes fases, o sentido dos acontecimentos se clarifica. Os acontecimentos não podem ser compreendidos senão quando referidos à totalidade de cada fase.

Mister se faz ressaltar que o método da redução sociológica é uma das grandes contribuições desse autor para os estudos organizacionais críticos (PAULA, 2005). Costa (2012) afirma que Ramos não deixou para as novas gerações uma obra redonda e acabada, mas ela é fundamental para refletirmos sobre a ciência na atualidade. E dela apreenderemos o conceito de consciência crítica apresentado na primeira lei - Lei do Comprometimento.

\section{MÉTODOS E PROCEDIMENTOS}

Revista Eletrônica Gestão e Serviços v.11, n. 1, pp. 2929 - 2945, Janeiro/Junho 2020. ISSN Online: $2177-7284$ e-mail: $\underline{\text { regs@ } @ \text { metodista.br }}$ 
Nesta seção, serão abordadas as ações metodológicas para a execução desta pesquisa, especificamente seu tipo, a definição de seu objeto, técnicas que foram usadas para a coleta de dados e suas posteriores análises, com o objetivo de identificar a convergência entre as produções científicas e o conceito de consciência crítica de Guerreiro Ramos.

A pesquisa pode ser caracterizada como descritiva, pois busca conhecer a realidade estudada, suas características, seus problemas, com base em determinada produção científica (VIEIRA, 2007). Quanto à abordagem, a presente pesquisa classifica-se como sendo qualitativa, pois pretende avaliar a qualidade das informações e ter acesso a percepção dos atores.

O objeto de pesquisa desse estudo é a produção científica em Administração. Para tanto, escolhemos, por questão de proximidade, a produção dos grupos de pesquisa cadastrados no $\mathrm{CNPq}$ da área de Administração da Universidade Federal de Minas Gerais (UFMG). Em 2017, foi acessado o sítio eletrônico do Diretório de Grupos de Pesquisa vinculados ao CNPq e realizada a coleta de informações sobre a universidade acerca dos seus grupos de pesquisa, a saber, nome do grupo, líder e segundo líder dessa universidade pública, totalizando 25 grupos.

A partir do nome do grupo bem como de seu líder, buscou-se na Plataforma Lattes a produção de artigos científicos, tendo os seguintes critérios para a seleção:

(a) tempo: recorte temporal será de dez anos, compreendendo os trabalhos de 20062016;

(b) natureza: publicações em periódicos da área de administração conforme Qualis 2015;

(c) autoria: de pelo menos dois componentes dos grupos, incluindo o líder; e

(d) tipo: artigos empíricos, sendo assim, ensaios teóricos foram excluídos.

Com tais informações, foram excluídos: cinco grupos por estarem com informações desatualizadas no Diretório de Grupos de Pesquisa vinculados ao CNPq; um grupo, no qual o líder mudou da área da administração para a psicologia; e dois grupos que não tinham produções científicas com integrantes do grupo. Sendo assim, foram coletados 303 artigos desses 19 grupos de pesquisa restantes.

Após a coleta dos 303 artigos, estes foram submetidos à uma análise livre, e consequentemente não exaustiva, do conceito de desenvolvimento de Celso Furtado. Realizou-se uma espécie de varredura, objetivando-se encontrar o conceito de desenvolvimento. Como resultado, obteve-se apenas quatro artigos. Após essa 
classificação, foi investigada a convergência entre tais produções e o conceito de consciência crítica de Guerreiro Ramos (1958), expressa na primeira lei da redução sociológica. Assim, foram selecionados os artigos. Os quatro artigos de um grupo de pesquisa antes relidos, foram analisados novamente, a partir do conceito de Ramos (1958) sobre o comprometimento e autonomia de pensamento e dos preceitos de compromisso com a organização, atitude de autonomia, oposição à fixação pelo estrangeiro e assunção direta do conteúdo exógeno.

\section{RESULTADOS}

A intenção é delimitar, a partir dos artigos que tratam do conceito de desenvolvimento, a presença da consciência crítica da construção destes. Entende-se que ambos os conceitos - desenvolvimento e consciência crítica — podem guiar a ação intelectual dos grupos de pesquisa da Administração para que contribuam para o fomento do desenvolvimento nacional. Sendo assim, foram selecionados quatro artigos para essa análise apresentados a seguir.

\section{Artigo 1: Análise dos Conselhos Gestores de Políticas Públicas à luz dos Relatórios de Fiscalização da Controladoria Geral da União}

Ao apresentar as dificuldades dos conselhos de saúde e de outros setores, os autores se fundamentam no histórico do autoritarismo vivenciado no Brasil. Em outros termos, trata-se de uma reflexão dos condicionamentos para a situação vivenciada, ou seja, o surgimento da consciência crítica para a compreensão do objeto em análise.

O objeto de estudo - conselhos gestores de políticas públicas - são vistos, pelos autores do artigo, como detentores de autonomia, atuação transparente e de integração social e, sobretudo, garantidores da legitimidade das representações da sociedade civil. Tais requisitos tem aderência com a primeira lei da redução sociológica de Ramos (1958), a lei do comprometimento, que pressupõe ao cientista social a adoção de uma posição de engajamento ou de compromisso consciente com o seu contexto.

Ademais, o trabalho tem como objetivo maior, incentivar a ampliação da participação da população e engajamento nos processos de formação de agendas, implementação e avaliação de políticas públicas. Mesmo diante do papel idealizado dos conselhos, os autores lançam luz às virtualidades que possam estar obscurecidas na 
conduta destes, por meio daquilo que Ramos (1958) chamou de comprometimento sistemático.

Pode-se afirmar que há certa oposição (ou ponderação) ao conteúdo estrangeiro, pois os autores, ao delimitarem a fundamentação teórica, percorrem diversos estudiosos (inclusive estrangeiros) para se apropriarem do conceito, por exemplo, de governança. Este movimento fica claro nos trechos: “(...) considerando o contexto brasileiro, adotase, para fins deste trabalho, a governança (...)" (MARTINS, CKAGNAZAROFF, LAGE, 2012, p. 227), “(...) considerando que a governança democrática brasileira está intrinsicamente relacionada às questões de descentralização, outros problemas são destacados (...)” (MARTINS, CKAGNAZAROFF, LAGE, 2012, p. 228).

Portanto, a partir dessa análise, pode-se afirmar que o trabalho atende aos quesitos da primeira lei, a lei do comprometimento, conforme enunciada por Ramos (1958). Apresenta (1) resgaste da história da realidade brasileira, (2) compromisso com a sociedade, (3) indicação de falhas e limitações, a fim de superá-las, e (4) assimilação não mecânica das contribuições cientificas estrangeiras.

\section{Artigo 2: “... Porque são reis do seu território”. Configurações subjetivas na gestão metropolitana em Vitória-ES.}

O texto se justifica pela carência de estudos da área da gestão que preconizam as dimensões cultural e histórica. O resgaste histórico da realidade é condição inicial para o surgimento da consciência crítica, quando um sujeito ou um grupo social reflete sobre os determinantes da realidade, de acordo com Ramos (1958). Além da base teóricometodológica utilizada ser a teoria da subjetividade numa perspectiva histórico-cultural, um trecho do referencial teórico marca fortemente tal posicionamento: “(...) a busca por compreensão das diversas facetas que compõem o problema pela via da subjetividade, o que implica considerar aspectos culturais e históricos que conformam as decisões sobre a gestão de metrópoles, parece promissora" (SILVEIRA, CKAGNAZAROFF, 2016, p. 203).

O objeto de pesquisa do artigo — o desenvolvimento de Vitória - ES — é um indicativo da adoção de uma posição de engajamento ou de compromisso consciente com o seu contexto. Bem como as sugestões de estudos futuros, “(...) elas indicam a necessidade de aprofundamento do estudo no problema da gestão metropolitana em 
Vitória, o que pode ser feito a partir da incorporação de novos sujeitos de pesquisa, especialmente cidadãos envolvidos diretamente no problema, como, por exemplo, profissionais e usuários do sistema de transportes públicos, moradores em regiões de risco, pessoas atingidas por problemas como violência, falta de moradia, falta de serviços de educação e saúde de qualidade" (SILVEIRA, CKAGNAZAROFF, 2016, p. 201).

Pode-se afirmar que há certa oposição (ou ponderação) ao conteúdo estrangeiro, pois os autores, ao delimitarem a fundamentação teórica, percorrem diversos estudiosos (inclusive estrangeiro), mas retomam autores que se dedicam ou se dedicaram ao contexto brasileiro. Este movimento fica claro nos trechos: “(...) Entre inúmeros estudiosos que se debruçaram sobre o caso brasileiro, Souza (2015) o faz partir de uma visão no campo da autonomia (...)" (SILVEIRA, CKAGNAZAROFF, 2016, p. 202). Contudo, sem ignorar o contexto internacional, “(...) no plano mundial, a ideia de colaboração e cooperação para a gestão metropolitana" (SILVEIRA, CKAGNAZAROFF, 2016, p. 203), que se trata de uma condição importante na atualidade. Outro trecho que caracteriza tal preocupação, mas agora com os vizinhos latino-americanos: “(...) destacam que a América Latina tem sido caracterizada por governança metropolitana centralizada" (SILVEIRA, CKAGNAZAROFF, 2016, p. 203).

Portanto, a partir dessa análise, pode-se afirmar que o trabalho atende aos quesitos da primeira lei, a lei do comprometimento, conforme enunciada por Ramos (1958). Apresenta (1) resgaste da história da realidade brasileira, (2) compromisso com a sociedade, e (3) assimilação não mecânica das contribuições científicas estrangeiras. $\mathrm{O}$ artigo não faz a indicação de falhas e limitações, a fim de superá-las, apenas as evidencia.

\section{Artigo 3: Prefeituras priorizam o desenvolvimento local? Um estudo qualitativo do caso de Montes Claros/MG de acordo com a visão de gestores públicos locais}

O trabalho tem aderência com o conceito de desenvolvimento, ao alertarem para o mito do desenvolvimento econômico. Conforme esse trecho, “(...) há sempre uma tendência dos pesquisadores de observar aspectos materiais relacionados à renda [ao tratar de desenvolvimento] - pela simples razão de que analisar dados empíricos e 
quantificáveis de renda é mais fácil do que pensar o desenvolvimento de forma qualitativa" (COUTO, CKAGNAZAROFF, 2016, p. 226). Contudo não se apropria da lei do comprometimento no momento em que não retomam a historicidade numa perspectiva reflexiva.

O trabalho apresenta compromisso com a sociedade no próprio objeto de estudo - gestão pública priorizando o desenvolvimento. Pode-se afirmar que não há uma oposição (ou ponderação) ao conteúdo estrangeiro, pois os autores, ao delimitarem a fundamentação teórica, se apropriam do conceito de desenvolvimento de Ignacs Sachs, — “(...) este artigo coaduna com a posição de Sachs (1993), para que o desenvolvimento se distinga do conceito de crescimento social razoável, uso prudente dos recursos naturais e eficiência econômica" (COUTO, CKAGNAZAROFF, 2016, p. 227) - e não apresentam as limitações de tal aporte teórico para as realidades latinoamericanas. Já a respeito do conceito de desenvolvimento local, percorrem diversos estudiosos, contudo, não deixam clara a escolha teórica, tendo em vista a realidade brasileira ou latino-americana. Sendo assim, não é possível afirmar que haja uma assimilação não mecânica das contribuições científicas estrangeiras e nem mesmo a indicação de falhas e limitações destas.

De maneira geral, o artigo traz em seu bojo uma preocupação importante para a gestão pública brasileira, contudo não o faz com compromisso e engajamento crítico proposto por Ramos (1958), por não trazer a historicidade e as características peculiares da região analisada - Montes Claros. O trabalho tem aderência com a proposta de Celso Furtado de criatividade e desenvolvimento, mas não traz a perspectiva crítica proposta por Guerreiro Ramos.

\section{Artigo 4: Uma análise do desenho institucional do projeto para combater a pobreza rural em Minas Gerais, Brasil}

Não houve um resgaste da realidade brasileira no que tange a participação dos cidadãos na tomada de decisão pública. Apelo latente de Guerreiro Ramos na década de 40, e que de acordo com Costa (2012), ainda é esquecida por muitos. Há apenas um apontamento da seção introdutória: “(...) No contexto da democratização do Estado no Brasil, que remonta à década de 1980, se engendra uma nova dinâmica de relacionamento entre Estado e sociedade civil por meio de diferentes mecanismos de incentivo a participação 
política, que procuraram não só democratizar o Estado, mas politizar a sociedade civil (...)”(FREITAS, CKAGNAZAROFF, FREITAS, 2014, p. 152).

O objeto de estudo do trabalho indica a preocupação com a sociedade, conforme indicado no trecho: “(...) O Projeto de Combate a Pobreza Rural (PCPR) de Minas Gerais, objeto de análise deste trabalho [....]. O Projeto visa diminuir as condições de pobreza dos agricultores através do financiamento não reembolsável de projetos produtivos, sociais e de infraestrutura básica" (FREITAS, CKAGNAZAROFF, FREITAS, 2014, p. 153).

$\mathrm{Na}$ busca pelo referencial teórico, os autores percorrem estudiosos e mais uma vez indicam as problemáticas trazidas (ou deixadas) pelas perspectivas naturalizadas: “(...) refletir sobre o desenvolvimento requer considerar noções e perspectivas naturalizadas, como progresso e crescimento, contendo uma ideia intrínseca de que desenvolvimento gera mudança (...)" (FREITAS, CKAGNAZAROFF, FREITAS, 2014, p. 154). Há claramente indicação de falhas e limitações no que tange a participação da sociedade civil e há proposta para superá-las. Mesmo que não haja um aprofundamento das necessidades locais. Veja: “(...) elemento central nessa discussão (...) é a ideia de que a participação da sociedade civil não garante por si própria, a reversão de uma lógica de poder em direção ao aprofundamento da democracia e efetividade da ação por parte do Estado. Há que se qualificar essa participação e apurar os elementos constitutivos de uma efetiva reformulação nos mecanismos de decisão (...)" (FREITAS, CKAGNAZAROFF, FREITAS, 2014, p.153). Outro trecho: “(...) seria ingênuo esperar a participação política em grande escala sem criar as condições necessárias para tal envolvimento (...)” (FREITAS, CKAGNAZAROFF, FREITAS, 2014, p.157).

Quanto ao programa de combate à pobreza, houve comparações com as experiências nordestinas, para assim evitar a repetição de falhas semelhantes. “(...) as experiências no Nordeste mostraram ainda que os investimentos das comunidades, gerando economia nos custos, e aumento das propriedades comunitárias, levando assim a uma melhor sustentabilidade dos investimentos (...)" (FREITAS, CKAGNAZAROFF, FREITAS, 2014, p.158).

Portanto, a partir dessa análise, pode-se afirmar que o trabalho atende aos quesitos da primeira lei, a lei do comprometimento, conforme enunciada por Ramos (1958). Apresenta (1) resgaste da história da realidade brasileira, (2) compromisso com a sociedade, (3) indicação de falhas e limitações, a fim de superá-las, e (4) assimilação 
não mecânica das contribuições cientificas estrangeiras.

\section{CONSIDERAÇÕES FINAIS}

A intenção desse estudo foi delimitar, a partir dos artigos que tratam do conceito de desenvolvimento, a presença da consciência crítica da construção destes. Entende-se que ambos os conceitos - desenvolvimento e consciência crítica - podem guiar a ação intelectual dos grupos de pesquisa da Administração, para que contribuam para o fomento do desenvolvimento nacional. Em decorrência do filtro aplicado na etapa anterior - a presença do conceito de desenvolvimento, a partir da perspectiva teórica de Celso Furtado - foram selecionados quatro artigos dentre os 303 artigos separados para tal análise.

Buscaram-se elementos da primeira lei da redução sociológica de Guerreiro Ramos (1958), que fora enunciada da seguinte maneira: nos países periféricos, a ideia e a prática da redução sociológica somente poderiam ocorrer ao cientista social que tivesse adotado sistematicamente uma posição de engajamento ou de compromisso consciente com o seu contexto. Para tanto, utilizou-se três dimensões de análise: (1) resgaste da história da realidade brasileira, (2) compromisso com a sociedade, (3) indicação de falhas e limitações, a fim de superá-las, e (4) assimilação não mecânica das contribuições científicas estrangeiras.

Dentre os quatro trabalhos analisados, dois destes podem ser aplicados na Lei do Comprometimento - número muito baixo perto do tamanho da amostra analisada. Nas ciências administrativas, a expansão global da academia e do conhecimento intensificou a hegemonia anglo-americana ao fortalecer uma tendência de integração e pretensa universalização, inibidora de uma produção local que a desafie.

É preciso redefinir o valor do conhecimento científico como bem comum. De escrever sobre temáticas que interessam a cada país, aproximando-se assim da realidade brasileira e encontrando a pertinência sociocultural, a partir da consciência crítica. Nos termos de Ramos (1958), aquela surge quando um grupo social reflete sobre os determinantes exteriores e se conduz diante deles como sujeito. Naturalizar os determinantes e suas práticas não podem ser caracterizados como um modo radical de apreender os fatos.

Este trabalho se coloca como uma tentativa de criar um critério disparador de 
um trabalho científico, qual seja, visar o desenvolvimento bem como a consciência crítica. Defende-se que mesmo diante da diversidade paradigmática esses critérios devem ser observados com vistas ao desenvolvimento do país e melhoria da qualidade de vida. Pois, não é possível neutralizar os efeitos da nossa visão de mundo sobre a atividade científica. Vivemos necessariamente a visão de mundo de nossa época e de nossa nação, pois nos integramos na totalidade de mundo de um modo não intelectual (RAMOS, 1958). A guisa de exemplo, pode-se citar a utilização do quadro teórico de referência apresentado como parâmetro para que futuros pesquisadores ou pesquisadoras conheçam com profundidade as pesquisas realizadas nos programas de pós-graduações e seus grupos de pesquisa para assim fazer a escolha mais adequada de onde ingressar.

Por outro lado, devemos registrar os limites deste trabalho, quanto à quantidade de trabalhos analisados bem como a ampliação da análise a partir das demais leis da Redução Sociológica.

\section{REFERÊNCIAS BIBLIOGRÁFICAS}

AZEVÊDO, A.; ALBERNAZ, R. O. A redução sociológica em status nascendi: os estudos literários de Guerreiro Ramos publicados na revista Cultura

Política. Organizações \& Sociedade, Salvador, v. 17, n. 52, p.47-68, 2010.

BERGUE, S. T.; KLERING, L. R. A redução sociológica no processo de transposição de tecnologias gerenciais. Organizações \& Sociedade, Salvador, v. 17, n. 52, p. 137 $155,2010$.

COSTA, F. L. da. Guerreiro Ramos: teoria e prática da sociologia em mangas de camisa.

COUTO, F. F.; CKAGNAZAROFF, I. B. Prefeituras priorizam o desenvolvimento local? Um estudo qualitativo do caso de Montes Claros/MG de acordo com a visão de gestores públicos locais. Administração Pública e Gestão Social, v. 8, n.1, p. 225-234, 2016.

FREITAS, A. F.; CKAGNAZAROFF, I. B.; FREITAS, A. F. Uma análise do desenho institucional do projeto para combater a pobreza rural em Minas Gerais, Brasil.

Agroalimentaria (Caracas), v. 20, n.1, p. 151-166. 2014.

MARTINS, P. E. M.; MUNTEAL, O. (Org.). O Brasil em evidência: a utopia do desenvolvimento. Rio de Janeiro: FGV Editora, 2012. p. 472-485.

MARTINS, P. E. M. Alberto Guerreiro Ramos: um guerreiro exilado. In.: MARTINS, P. E. M.; MUNTEAL, O. (Org.). O Brasil em evidência: a utopia do desenvolvimento. Rio de Janeiro: FGV Editora, 2012. p. 434-439. 
MARTINS, S.; CKAGNAZAROFF, I. B.; LAGE, M. L. C. Análise dos Conselhos Gestores de Políticas Públicas à luz dos Relatórios de Fiscalização da Controladoria Geral da União. Administração Pública e Gestão Social, v. 4, n.1, p. 221-245. 2016.

MISOCZKY, M.C. Sobre o centro, a crítica e a busca da liberdade na práxis acadêmico. Cadernos EBAPE.BR, Rio de Janeiro, v. 4, n. 3. 2006.

PAULA, J. A. Brasil: passado e futuro. In.: SOUZA, Pedro d. (Org.). Brasil, sociedade em movimento. São Paulo: Paz e Terra. 2015. p. 13-22.

PAULA, A. P. P. Por uma nova gestão pública: limites e possibilidades da experiência contemporânea. Rio de Janeiro: FGV. 2005.

RAMOS, A. G. A redução sociológica. 3 ed. Rio de Janeiro: Editora UFRJ. 1958.

SANTOS, R. S. Em busca da apreensão de um conceito para a administração política. Revista de Administração Pública, v. 35, n. 5, p. 49-77, 2001.

SILVEIRA, R. Z.; CKAGNAZAROFF, I. B. Porque são reis do seu território. Configurações subjetivas na gestão metropolitana em Vitória/ES. Salvador: Gestão \& Planejamento, v. 17, n.1, p. 198-212. 2016.

TENÓRIO, F. G. O drama de ser dois: um sociólogo engravatado. In.: MARTINS, P. E. M.; MUNTEAL, O. (Org.). O Brasil em evidência: a utopia do desenvolvimento. Rio de Janeiro: FGV Editora. 2012. p. 440-471.

VIEIRA, A. M. Cultura organizacional em instituições de ensino: mapeamento e análise descritivo-interpretativa da produção acadêmica (1990-2005). 2007. Tese (Doutorado em Educação) Universidade Estadual Paulista (UNESP), Marília, 2007.

VIEIRA, A. M.; RIVERA, D. P. B. A Hermenêutica no Campo Organizacional: duas possibilidades interpretativistas de pesquisa. Revista Brasileira de Gestão de Negócios, v. 14, n. 44, p. 261-273, 2012. 